\title{
Barriers to Global Electronic Commerce: A Cross-Country Study of Hong Kong and Finland
}

\author{
Ali F. Farhoomand \\ School of Business \\ University of Hong Kong \\ Virpi Kristiina Tuunainen \\ Electronic Commerce Institute \\ Helsinki School of Economics and Business Administration \\ Lester W. Yee \\ Mathematics and Science Division \\ Babson College
}

\begin{abstract}
So far electronic commerce has primarily been limited to electronic business-to-business transactions and small, but quickly growing, consumer-oriented activities on the Internet, such as electronic advertisements mated with the traditional mail-order operations. What lies ahead in the future is a concept of true global electronic commerce (GEC), in which firms will exploit a virtual value chain to migrate much of their value-adding activities from the physical marketplace to the virtual marketplace. The capability for business concerns to be able to reach out to a global business community at a relatively small cost is very attractive and promises to transform international business. Despite this realization, it has become increasingly evident that the proliferation of GEC is dependent on resolution of a myriad of technical, organizational, economic, cultural, political, and legal issues.

In this study, field studies of 10 companies in Hong Kong and Finland were conducted with an eye toward identifying the major barriers that have hindered or slowed down the wide acceptance of electronic commerce across borders. In addition to several country-specific barriers to GEC, resistance to change, lack of education about the potentials of GEC, and lack of flexible software were found to be the key inhibitors to the orderly acceptance and deployment of computer-mediated commerce at the global level.
\end{abstract}

\footnotetext{
This project was financially supported by a grant from the Hong Kong Research Grants Council. Correspondence and requests for reprints should be sent to Ali F. Farhoomand, School of Business, Pokfulam Road, Hong Kong. E-mail: ali@business.hku.hr
} 
global business, electronic commerce, barriers, inhibitors, Finland, Hong Kong

\section{INTRODUCTION}

In recent years, there have been a large number of changes in the areas of electronic commerce and international trade. Broadly speaking, electronic commerce is defined to include any form of economic activity conducted via electronic connections. The bandwidth of electronic commerce spans from electronic markets to electronic hierarchies and also incorporates electronically supported entrepreneurial networks and cooperative arrangements [1]. Electronic commerce today consists of two interrelated strands of network computing: an expanded use of open networks by traditional electronic data interchange (EDI) to interconnect private networks with the Internet, and an entirely new marketplace on the Internet using World Wide Web (Web) technology [2].

On the one hand, phenomenal worldwide business growth of the Internet and the rapid advances in Web technologies and standards have effected new business opportunities and challenges. On the other hand, due to globalization of business, a growing number of firms have been forced to seek global economies of scale, rapidly tailor their products to local foreign markets, and meet the varied needs of global customers [3]. These internationally active firms have been compelled to rely increasingly on information technology (IT) to coordinate their internal and business transactional activities at many sites in various countries. As a result, it has become increasingly important for these firms to understand various issues affecting global electronic commerce (GEC), such as the rules that govern the flow and use of information within and across borders [4].

To reap the full benefits of electronic commerce, companies need to consider presale and postsale issues as well as numerous activities related to different parts of their value chain [5]. So far GEC has primarily been limited to electronic business-to-business transactions; that is, EDI and small, albeit quickly growing, scaled consumer-oriented activities on the Internet, such as electronic advertisements mated with traditional mail-order operations. More recently, efforts have been underway to conduct true GEC, in which international transactions are facilitated and supported or conducted solely through a growing number of technology applications, including, for example, search tools such as browsers, search engines, online databases, electronic catalogs, and multiple-listing services; exchange mechanisms such as 1-800 numbers, credit cards, debit cards, smart cards, EDI, automated teller machines, and computer reservation systems; and electronic payment, monitoring, and enforcement systems such as electronic data-capture credit card authorization, electronic funds transfer, and automated clearinghouses [6].

Through an empirical investigation of various stakeholders involved in GEC, this article tries to shed some light on the barriers to GEC. Field studies of major stakeholders, such as multinational companies, telecommunication service providers, and government bodies in two countries were conducted to paint a more accurate picture of these barriers. Based on this, we identify the key barriers and raise several questions that have important implications for accelerating the widespread acceptance and diffusion of electronic trade at the global level. 


\section{FRAMEWORK FOR THE STUDY}

Kalakota and Whinston [7-9] are among the pioneers in the emerging field of electronic commerce. Their generic framework for electronic commerce builds on convergence of technical, policy, and business concerns. The two pillars supporting all electronic commerce, applications, and infrastructure are public policy (to govern such issues as universal access, privacy, and information pricing) and technical standards (to dictate the nature of information publishing, user interfaces, and transport in the interest of compatibility across the entire network) [8]. Along the same lines, Zwass [10] presented a framework of electronic commerce consisting of three metalevels: infrastructure, services, and products and structures, where products and structures of electronic commerce cover three categories: consumer-oriented commerce, business-to-business commerce, and intraorganizational business.

The capability for business concerns to be able to reach out to a global business community at a relatively small cost is very attractive and promises to further promote entrepreneurial and creative businesses in a virtual marketplace [11]. Electronic commerce denotes the seamless application of information and communication technology from its point of origin to its endpoint along the entire value chain of business processes conducted electronically and designed to enable the accomplishment of a business goal [1]. In this light, many firms are exploring ways to exploit a virtual value chain to migrate much of their value-adding activities from the physical marketplace to the virtual marketplace. As with any innovation, however, the diffusion of GEC is surrounded by a wide range of difficulties. Solutions to buying and selling in these environments, how to handle electronic cash transactions, various security issues, and other topics are emerging [1].

In light of the recent surge of interest in GEC, it has become increasingly important to identify the major barriers that are hindering the wide acceptance of electronic commerce across borders. To gain a comprehensive view on these issues, focus on technical, legal, and business concerns alone is not sufficient. Consequently, we view these issues, as seen in Figure 1, as broadly classified into technical, political, cultural, economic, and legal issues [12].

Technical issues encompass factors such as inadequacy of telecommunications links, incompatibility of hardware and software, lack of universal communications protocols, and security concerns [13]. Because of the differences in the technological infrastructures built in various countries, the business processes in the host country as well as the intermediaries need to be systematically integrated at the technical level. Political issues entail such aspects as government attitude toward foreign firms, regulations and public policies affecting transborder data flow, foreign use and ownership of telecommunications infrastructure, customs clearance, and financial payment transactions [14]. Similarly, cultural factors, notably language, have been identified as pivotal in the proliferation of telecommunication networks [15] and, by extension, global electronic trading. The economic environments of participating countries also affect the degree of acceptance and use of GEC. General economic factors such as inflation rate, currency exchange and taxation laws, and availability of logistics and distribution infrastructures play major roles in transnational trade [14]. Finally, to conduct electronic commerce globally, an effective legal mechanism 


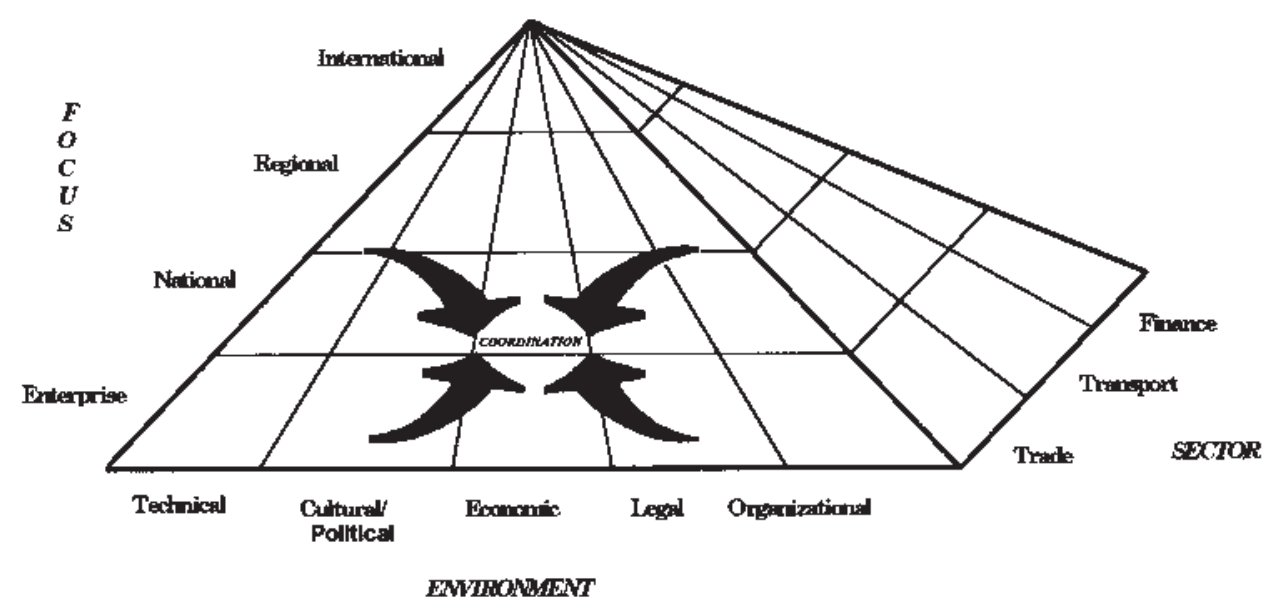

Figure 1. A classification of electronic commerce issues.

needs to be put in place to address various legal issues, such as those surrounding intellectual property and intrafirm transborder data flows [11].

\section{RESEARCH METHODOLOGY}

To better understand the intertwined myriad of barriers to global trade, an empirical investigation in Hong Kong and Finland was undertaken. Government officials and representatives of multinational companies that are directly involved in GEC were interviewed. Altogether, five case organizations were selected from each country with a view toward gaining a more in-depth insight into the technical, cultural, political, economic, and legal issues related to GEC.

The field studies were carried out using the guidelines offered by Yin [16] and elaborated by Garaway [17] for conducting cross-cultural case study research. These frameworks advocate a multiple-case research design in which data gathered from single cases are pattern-matched to construct an overall cross-case portrait of the phenomenon under study. Researchers can then draw cross-case conclusions, identify policy implications, and develop recommendations for practice. At the single-case level, the design reflects the conceptualization of case-site uniqueness, and at the cross-case level efforts are made to use replication as a means to formulate aggregate findings.

In this study, 10 organizations representing major stakeholders of GEC in two countries were interviewed. Hong Kong, being the busiest container port in the world (processing 200 million tons of container goods annually) and a major financial center, was chosen as one of the research sites. Finland was chosen because its population is roughly the same size as that of Hong Kong. Finland, a country with state-of-the-art public telecommunications networks and one of the highest numbers of both Internet and mobile telephone connections per capita in the world, is active both in importing and exporting, particularly in high technol- 
ogy. It should be noted that in both countries a large percentage of the companies are small and medium-sized enterprises (SMEs). In Finland most companies are computerized at least to the extent of having a personal computer for office routines. In Hong Kong, on the other hand, most of the small companies operate without the use of computers.

Only organizations thought likely to be major players in GEC were selected. These firms represented trade, banking, transport, government, Internet service providers (ISPs), and trade-supporting organizations. Most of the case organizations have some exposure to EDI activities and a basic orientation and understanding of the value of ITs for trade. Some of the more progressive organizations have a presence on the Internet, mostly for marketing purposes, and in the case of governmental agencies as a public service information server. For the sake of brevity, short descriptive code names (aliases) are used through the case descriptions. The code names, real organization names, and a short description of the organizations participating in the study are presented in Appendix A. Detailed descriptions of the companies are provided in Appendix B.

The interviewees were at the executive rank, including a chief executive officer, several executive directors, and several managers. Interviews usually lasted 1 to $2 \mathrm{~h}$. In a typical interview setting, one of the researchers would conduct the interview as the other kept notes. An interview outline was used to guide the interviews and to elicit perceptions and stated realities for the barriers to GEC. At the end of each interview, each respondent was asked to identify the top three barriers to GEC. All interviews were also tape recorded. The contents of these tapes were transcribed and subsequently used as supporting material in writing up individual cases.

To gain an insight into the order of importance of the issues, we highlighted the key issues from each interview, then combined these issues with the top three issues identified by each interviewee.

\section{RESEARCH FINDINGS}

The concept and role of GEC vary among the interviewees. The variation in the definitions stems from each organization's interest with respect to GEC. Consequently, the breadth of what GEC encompasses is different among different stakeholders. For example, Hong Kong Tradelink, which is heavily involved in EDI development and is responsible for setting up the territory's EDI gateways, considers GEC as EDI, fax, e-mail and "whatever else is around." Within these perspectives, GEC is seen as an innovation evolved from EDI, and the Internet as just another network transport medium. In contrast, both ISPs view GEC as matching buyers with sellers who are transacting through an electronic broker (i.e., ISP). From the Hong Kong government's point of view, GEC is seen as trade activities representing repeat orders and not so much for one-time orders.

The results of the study are presented in the order of the combined importance of the key issues identified by the interviewees: technical, organizational, economic, political, cultural, and legal. 


\subsection{Technical Barriers}

"Interest in proven technology is better than being a guinea pig" (HK Tradelink). ${ }^{1}$ Many technical problems still prevail and are clearly seen as major barriers to GEC. On the whole, the most significant barriers to the use and proliferation of GEC are perceived to be of a technical nature. Not only did technical issues come up throughout our open discussions with the interviewees; they were also cited frequently among the top three key issues. These technical issues fall into five broad categories: infrastructural issues, organizational-level problems related to the integration of new GEC solutions to existing legacy systems, standards issues, issues related to the capabilities of the Internet, and security concerns.

4.1.1 Establishment of Infrastructure. "Infrastructure is the enabling factor, a prerequisite for fluent electronic trading" (HK Information Technology Services Department [ITSD]). When operating across borders, the national infrastructures of participating countries have critical impacts on the feasibility of GEC. It has long been argued that GEC is not possible unless all participating countries have adequate technical infrastructure in place to deal with cross-border data [18]. A case in point is the situation of EDI in Hong Kong, where in the absence of a viable EDI gateway, it is estimated that $600 \%$ of all cargo movements are delayed up to 2 days because trade documents are being processed manually rather than electronically via EDI [19]. Similarly, despite advanced facilities in Finland, the country's trade is somewhat hampered because of inadequate infrastructures in some southern and eastern European countries. This concern was voiced especially by Finnish Customs, which has experienced problems in the increasingly important communication between the customs departments of different countries.

The use of the Internet is partly curtailed by insufficient bandwidth needed for multimedia transmissions [10]. Other problems and barriers with the Internet are the difficulty monitoring site use, lack of universal access, and difficulty in obtaining reliable searches [20]. Furthermore, the core networks and services that support applications are not very reliable; the technology to create an open architecture that is resistant to accidental or intentionally induced outages does not exist at this time; the technology to achieve interoperability among applications, services, and technologies does not exist at this time [9].

As increasing numbers of enterprises start conducting their global business electronically, telecommunications carriers and ISPs will have more incentive to address some of the country-specific infrastructural problems. For example, one of the ISPs in Hong Kong is in the process of developing its own Internet backbone connecting the United States, Europe, Taiwan, Australia, China, Thailand, and Singapore. The HK ISP is also investigating alternate sources of telecommunications, such as satellite, with a view to reducing costs. Despite these commercial initiatives, the question of technological infrastructure still remains a national issue [12].

4.1.2 Integration of Legacy Systems. "The problems related to the incompatibility of the Group's information systems and those of the retailers have led

${ }^{1}$ Throughout this article we use direct quotations from our interviews with respondents in our sample. 
us to rebuild our information infrastructure and finance the same for the retailers" (Finnish Wholesaler). How to integrate an existing business system with the new technologies required by GEC is another pressing issue both in Hong Kong and Finland. The problem is currently rooted in integrating EDI transactions into legacy mainframe systems. Even though these systems have been the workhorse of the banking, finance, and insurance industry as well as the government, they do not give large corporations a good cost-benefit ratio, and they do not give much flexibility to integrate and upgrade systems. It is believed, however, that this problem will be gradually solved as more and more companies adopt standardized open systems solutions such as those promised by intranet technologies. Interestingly, in the absence of the preponderance of legacy systems in some less advanced countries, the integration problem seems less severe in these countries.

4.1.3 Availability of Applications and Standards. "There is a severe absence of natural-language supported applications and related standards" (HK ITSD). Support for national languages in software is necessary for true GEC. The general perception in Hong Kong is that there are few such applications, in particular those that support national languages such as Chinese. Localization of programs to European languages such as Finnish is generally a simple task, but the situation is drastically different with iconographic languages typical to the Far East and southeast Asia. Problems with the language support are due in part to the lack of language-specific standards, particularly in EDI, something that is expected to be resolved with the development and diffusion of the United Nations-supported Electronic Data Interchange for Administration, Commerce, and Transportation (EDIFACT).

Another issue relates to interoperability of standards necessary to transact across networks (e.g., the Internet). HK ISP believes that in the absence of a clear definition and common standards for online commerce for the Internet, public perception is one of suspicion. A frequent comment heard by HK Tradelink on the same theme is that EDI standards have not been well established, thus providing enterprises with an excuse for their own lack of core competencies in the area.

4.1.4 Capabilities and Performance of the Internet. "The performance aspects of the Internet is a problem as its original design was not meant to handle this level of activity" (HK ISP). "Message delivery systems across proprietary networks have confirmation mechanisms, but how can we have guaranteed service across the Internet?" (HK AirCargo). Another technical issue is the capability, reliability, and maturity of the Internet technology to support GEC. It is believed that the Internet needs to be able to provide integrated support for GEC services (e.g., EDI) to be regarded as a viable backbone for conducting electronic commerce. Standards for trade over the Internet are not yet mature compared with established standards (e.g., EDIFACT). For example, according to HK AirCargo, one of the benefits of having and using industry-based standards for EDI is that it is considered a guaranteed service. Information is transacted and the standard protocols serve to verify the transaction. A critical question is how this 
can be achieved with the Internet: Will the customer be asked to update a central Web server each time he or she wants to confirm the receipt of information? Until such issues are addressed, the full acceptance of the Internet as a medium for EDI and GEC will be delayed.

4.1.5 Security. "There needs to be only one incident of malpractice and everyone would get scared" (HK ITSD). Unsecured transmission on the Internet is often cited as the main deterrent for a rapid growth of GEC. Although much progress is being made in terms of security, the Internet is still considered to pose a risk for commercial transactions. Although payment security usually means protecting sensitive information from eavesdropping and theft, a secure transaction has a broader set of requirements, including nonrepudiation, authentication, integrity, and confidentiality [2]. A global perception still exists that the Internet is wildly insecure. In general, little trust is given to the Internet, even though it is easier to tap a phone than the Internet. The security issue related to financial payment transactions is in particular of great concern. Furthermore, because security has to be uniform across all linked business partners for the network to be secured, HK AirCargo indicated that there needs to be a central authority or security hub that will play the role of security registration and managing officer for conflict resolution. It should be noted that some of these concerns may have been exaggerated because of some well-publicized hacking incidents. Nowadays security technologies such as pretty good privacy (PGP) are readily available and can be plugged into a Web browser, enabling a reasonably secure environment for business transactions. "The development of a safe Internet payment method is of crucial importance-only then will the volume of business in the Internet become significant" (Finnish Wholesaler).

The issue of secured payment is beginning to receive the due attention it deserves. The Finnish ISP, together with its parent company (a pan-European ISP) and DigiCash Corporation have now been the first in Europe to issue electronic cash (e-cash). Employing public key encryption, the company allows consumers to make payments from a computer to organizations that accept e-cash across a public network (e.g., Internet). Currency conversion from Finnish marks to any other world currency is done automatically, allowing a person to purchase goods and services around the world instantly.

Consider the case of HK ISP, which provides two online services: an airline reservation system and a movie theater seat reservation system. The firm decided to implement a two-level password security system for their customers, something that has proven to be sufficiently secure. They have also migrated their ISP services to a proprietary online operation similar to the online services provided by America Online and Compuserve. The change allows them to position themselves as a secure intermediary. Membership to HK ISP's services requires preregistering with a credit card to avoid the communication of credit card numbers across the Internet. These approaches are adopted because HK ISP believes that its customers and the general online Asian community would like to have access to GEC now, and they cannot wait for companies such as Microsoft, Visa, Mastercard, Netscape, and others to introduce an acceptable set of standards. 


\subsection{Organizational Issues}

Organizational issues manifested themselves in the form of resistance to change, lack of education, and lack of management education and commitment. Together, these issues were identified as the second most significant barrier to the adoption and proliferation of GEC.

4.2.1 Negative Attitudes, Lack of Knowledge, and Resistance to Change. "An advanced 24-hr dial-up online service system was developed for selected customers. The results were that half the customers used the service, but the rest preferred the old procedures. We believe that the problem is not with the system, but with the insufficient training of customer's personnel" (HK AirCargo). "Many companies still tend to think that there are only teenagers without credible buying power using the Internet" (Finnish Bank). Resistance to change, negative attitudes, and a general lack of education and understanding of IT generate a lot of excuses for not committing to GEC. For HK ISP, the average Asian consumer must be psychologically convinced that significant value can be attained through GEC for them to change their shopping habits. The attitudes of small firms are also influential in the diffusion of GEC, especially in Hong Kong. Smooth adoption and implementation of GEC are mainly a matter of understanding the value of doing business electronically. Because computer literacy among SMEs is generally low, they do not usually have access to expertise for addressing complex telecommunications issues. Curiously, this lack of expertise and knowledge about the new technologies among SMEs in turn slows down the growth of GEC among larger companies because of their business reliance on SMEs.

4.2.2 Lack of Management Commitment. "As a legacy of some 30 years of IT/IS departments, lack of top management commitment is still a considerable barrier to the development of electronic trading in many organizations" (Finnish Network Association). A firm that plans to adopt an electronic trading system has to manage aspects of integrating the new technology during the implementation process [21]. Adjusting the labor force may be socially or politically problematic for a firm, including managing the acceptance of workers to take training in a computerized technology. Problems may also arise as a result of inefficiencies in corporate information systems analysis and design or from a lack of top- management support [22].

The results of this study show that the level of commitment among the organizations toward GEC varies considerably. Interorganizational clashes are to be expected, as there will always be communication conflicts between business and IT people. Lack of top management commitment is still a considerable barrier to the development of electronic trading in many organizations. As expressed by the Finnish Wholesaler, many of their business partners (particularly the smaller firms) tend to lack management-level initiatives toward electronic commerce. Consequently they tend to direct their scarce resources to areas familiar to them. "Quite often the top management and business functions of the organization are interested, even enthusiastic, about the new possibilities of the Internet, but a conserva- 
tive IS department might be putting on the brakes on the development" (Finnish ISP). Having reaped considerable annual returns, the Finnish Wholesaler itself has fully embraced the value of EDI and IT. Investments in telecommunications and networking on the whole are given a top priority at the highest level. For HK Bank, one of the largest and the most profitable banks in the world, IT, and by extension GEC, are also perceived as indispensable parts of business.

\subsection{Economic Issues}

"In Asian countries cost of technology is high, but cost of labor is low. There is an imbalance among Asian and other countries" (HK Tradelink). "It is very hard tojustify the involvement in electronic commerce in monetary terms" (Finnish Network Association). Electronic commerce is driven on both buyer and supplier sides by a number of factors, including access to an affluent customer base and broader market reach, lower information dissemination and transaction costs, improved service, additional channels for customer feedback, and better facilitated consumer and market research [20]. However, the economic environment in general terms may influence the potential to set up the sophisticated operational processes in GEC. Factors such as level of economic development, population, gross national product, per capita income, literacy level, social infrastructure, membership in regional economic blocks, monetary and fiscal policies, currency convertibility, inflation, taxation system, interest rates, and wage and salary levels all may hinder transnational electronically mediated trading.

The architecture of electronic business networks will be critical in determining their economic impacts; how these networks are formed and ultimately joined together to comprise a national infrastructure will influence the cost of doing business. Their design will also affect the overall efficiency of the economy, the size and scope of markets, the ability to conduct trade, the distribution of economic costs and benefits throughout the economy, and the nature of work and the quality of jobs [6]. Events within the market and market structure are also experiencing changes due to the increasing utilization of modern telecommunication media [1].

The economic well-being of individual nations makes a difference in their ability to provide infrastructure needed for conducting international business electronically. In addition to the level of technological sophistication, other economic factors play an important role in the proliferation of intercountry electronic commerce. For example, the host country's memberships in regional or international economic blocks, differences in business practices, or differences in nature of competition in various countries can pose certain barriers to GEC. Consider that in India, availability and affordability of personal computers are major stumbling blocks for small producers.

In this study, economic issues were found to be the third most important set of barriers slowing adoption and diffusion of GEC. In Hong Kong, GEC is generally viewed as a costly initiative. In light of the short-term view of business activities in Hong Kong, GEC is being considered primarily by larger organizations; many small companies see little value in investing in GEC too early. Similarly, most companies in Finland are taking a wait-and-see attitude toward GEC, citing high costs and lack of government support. In many cases the companies are waiting for governmental 
agencies to take appropriate actions required for trade facilitation. For instance, businesses in both Finland and Hong Kong are waiting for customs to adopt an integrated clearance system that would support timely electronic clearance of goods.

The multinational banking sector is stridently more sensitive to the economic situation of countries. The economic level and hence existing infrastructures dictate the types of GEC operations that are possible. In developing countries there can be some resistance toward relinquishing advanced operations to foreign companies.

\subsection{Political Issues}

"The government is aware of the 'threat' of GEC/EDI on establishments. Currently within the government, thousands of workers are involved in manually processing the 15 million trade transactions annually" (HK ITSD). "Governments don't always see the benefits of electronic commerce; they are concerned about losing jobs" (HK Bank). The diffusion of GEC depends on the compliance of the participating nations' bureaucracies in their international trade agencies, many of which may have restrictive trade barriers. For example, as recognizing commercial partners and authenticating messages requires the use of encryption techniques, access to these encryption products should be as easy as possible for all engaged in legitimate commerce [23].

Nations impose cost, control, and privacy barriers to foreign trade generally, which can impact electronic trade especially [14]. Governments may institute national economic policy to protect selected domestic infant industries. There may also be preferential governmental treatment of local investors compared to foreign investors. For example, some governments have instituted principles to improve the competitiveness of local SMEs against foreign firms, which are often large multinational corporations with significantly greater business resources. In promoting the success of domestic industries, developing countries often define principles that guide the transfer of technology through business activities with foreign firms.

Deregulation of nationalized telecommunications operations can bring concern about the quality assurance of a critical element in GEC operations. Also regulations imposed by national quasi-commercial agencies such as the postal, telephone, and telegraph companies may also set further complications [14].

Politics of a country are largely pronounced by the actions of the country's government. In the same vein, governmental attitudes largely affect promotion or hindrance of GEC. It was found that the Hong Kong interviewees give more weight to political issues and governmental actions than the Finnish ones. In Hong Kong, a theme for minimum government intervention is the attitude, whereas in Finland there is a certain level of government involvement in trade in the form of laws, regulations, or subsidies.

The openness of the Internet brings about additional political considerations. Internet presence in politically conservative countries usually entails promotion of government or party propaganda. Certain countries have already imposed restrictions in terms of censorship, pornography, and more mundane issues such as the advertisement of alcohol. In Singapore, for example, the government is increasingly concerned about the information going out and requires communications licenses to operate. Interestingly, certain journals, such as the Far Eastern Economic 
Review, which have been given licenses to have limited printed circulation, are openly available in electronic form on the Internet.

4.4.1 Governmental Attitudes. "Best role for government is one of facilitator and supporter, but with no intervention in operation of businesses" (HK ITSD). "Government should be involved in the promotion of electronic commerce. It should use the carrot approach rather that the stick" (HK AirCargo). Governments wield considerable control over international trade by procedures activated at the border. These controls can uncouple the automatic and smooth-flowing processes of electronically designed delivery systems, thus eroding the commercial advantages of electronic commerce. Groupings of neighboring countries into privileged complementary trade blocks such as the one formed by the North American Free Trade Agreement or the various Asian cooperative export zones set favorable regulatory regimes for their intraregional economic interchanges, leaving in place the antiquated border procedures for firms' transactions from other countries [24]. The global move into electronically facilitated trade systems requires a liberalizing of the regulatory regimes for transborder trade to be applied to all trading partner nations, especially where the trade is in physical goods. Even trade in services is affected by border protocols such as immigration entry procedures that make entry or exit difficult for visiting service providers or the internationalist experts who work for local-foreign joint ventures. A local government's attitude regarding cost, control, protectionism, and privacy does create barriers to GEC. Although these factors instigate legitimate concerns, greater awareness and analysis in terms of costs-benefits and trade-offs need to be evaluated.

GEC involves the government on various fronts such as customs and infrastructural development. As such, the proliferation of GEC within a country hinges on government support. Similarly, protectionist attitudes and policies may hinder the proliferation of GEC at the international level. In light of employment concerns, almost every country wants to maximize exports and minimize imports. As such, the long-term benefits of adopting electronic trading may give way to short-term political or economic expediencies.

Governments do not always necessarily see the benefits of GEC because there is a protectionist attitude about relinquishing the technological edge to outsiders, as is the case in India and Japan. Telecommunications companies in some countries feel that networking operations are in their domain and that establishing a banking network is infringing on their turf. From HK Bank's perspective, such local telephone companies may not be able to provide sufficient security or reliable service for GEC.

Most countries are also concerned about the flow of data in and out of the country. The prevailing attitude of both governments and industries is that direct and free flow of trade information is a potential threat for them. "Transborder data flow seems to be a major obstacle, e.g., Singapore's government is very tight about information going out. Taiwan does not like the idea of encrypted data flowing through the country" (HK Bank). In addition, the restrictions on international financial payment transactions are still inhibiting the proliferation of GEC. Finally, there are concerns about the dominance of nationalized telecommunications carriers. Many countries have only one telecommunications carrier that usually operates in a monopolistic manner. Even though there are moves to deregulate telecommunica- 
tions industries in many countries, there is currently much concern about the dependency of businesses on the services offered by these monopolies.

Whereas HK ITSD firmly believes that the government has a role to play in trade and industry, especially in the area of EDI coordination, HK AirCargo feels that the Hong Kong government has not made the level of commitment necessary to support EDI and GEC. Realizing this, the company has sought industry-sponsored alternatives, such as the Société Internationale de Télécommunications Aéronautiques, which is a value-added network for central information exchange in the airline industry. This is largely congruent with the thoughts of the Finnish ISP, which believes that free market forces rather than central government coordination and control will result in the best outcomes.

4.4.2 Interagency Coordination. "Policy makers, chief executives, and trade associations all alike need to be educated about the benefits of GEC. For example, consider that within the United Nations work on developing EDI standards has been duplicated by two bodies. There seems to be poor coordination and cooperation" (HK Tradelink). "Establishment of industrial support organizations is needed. GEC success will come as each industry decidedly makes an effort to develop and manage a central coordination authority, educational programs, and to promote greater interaction with other industries and government, and ultimately accept some universal information processing standards" (HK AirCargo). Although technology can facilitate coordination, monitoring, and control in partnerships, and can reduce the risk of strategic reliance on relationships, it is ultimately the trust among partners that determines the success or failure of partnerships [25]. Many governments are deeply worried about taxable electronically enabled transactions flowing out of their countries. Because each country is taking a slightly different approach to the application of value-added tax, software developers and service providers are faced with the great challenge of developing appropriate mechanisms for tracking these nonstandard regulations [26]. Payment for goods or services may also be problematic where there are governmental barriers involving international financial payment transactions. Restrictions might complicate international payment transfers, which electronic commerce systems otherwise would conveniently automate from bank to bank as an integral element of the trading transaction [27].

The results of this study confirm the importance of coordination and cooperation among all the nations involved in GEC. There are many cultural and political factors that act as barriers to developing such cooperation. For example, some Finnish firms see tremendous opportunities in using electronic means to reach out to the Russian market but find their efforts hindered because of factors related to the still somewhat immature business culture of the postcommunism era.

It is widely believed that central coordination across different industries, in addition to the governmental adoption of industry standards and systems, will result in a higher general level of awareness, and thus smoother diffusion of GEC. Citing the United Nations efforts on the standardization of EDI that have resulted in two standards, HK Tradelink amplifies the difficulties in achieving such coordination. The conservative nature of most government bodies supports political environments that strive to maintain the status quo. In Finland, however, the different gov- 
ernment ministries have reached an agreement to work jointly-partly competing, but mostly cooperating - to build the necessary information infrastructure.

\subsection{Cultural Issues}

"Hong Kong people and businesses have an incredibly short-term attitude; to lot of small companies, long-term means next Tuesday" (HK Tradelink). There are cultural issues particular to a country, ethnicity, religion, and language that affect smooth exchange of goods and services between different countries. In an electronic environment, one of the most significant of these cultural issues relates to national languages, especially with Asian iconographic languages.

In a global economy composed of many more players and fewer standardized, mass-produced products, buyers and sellers must explore a multitude of options and be able to compare costs and values across languages and cultures and on the basis of different currencies [6, 8]. Many nations, having achieved economic status in the world community, seek to maintain their cultural identities, especially as embodied in their languages [28]. For the most part, when dealing with large national and multinational companies, trading in English is accepted, but as GEC moves down the supply chain to smaller companies, the need for national language support becomes critical [26]. A related challenge for electronic trading applications is a language translation interface, and especially efficient handling of iconographic languages such as Chinese, Japanese, and Korean [28].

With the ever increasing globalization of trade, English has become the lingua franca. Nevertheless, using English is still a problem to a certain degree in both Finland and Hong Kong. Language-related difficulties seem to be even more significant in larger countries with less exposure to English, especially in mainland China where people are increasingly more conscious of their own cultures and as such, desire to do business in their own native language.

The national language problem will be progressively relieved as technology in this area progresses. From the perspective of HK ISP, the real intercultural barriers lie with the insensitivity from one society to another: Different countries might require different products, a company might need different partners in different countries, and sometimes joint ventures need to be formed. Most important, it is usually true that the locals understand best what the locals buy, and country-specific issues have to be dealt with by local experts.

Electronic commerce can also bring about changes in shopping habits in different countries and regions. In Asia, for example, the general public does not have an established mail-order mentality, and there is not a sufficiently developed infrastructure to support it. In Hong Kong, for example, shopping is regarded somewhat as a social pastime, as it allows people to get out of their often very small apartment, and feel and touch the merchandise before buying it. In Finland, on the other hand, where the geographical distances are greater and the density of larger cities is lower, mail-order shopping has long traditions. Hence, the Internet is regarded by many companies as a convenient additional tool in the still growing mail-order business. 
An important finding of this study relates to the hierarchy of the issues perceived in Hong Kong and Finland. For example, in Hong Kong, resistance to change is regarded as the most influential barrier to GEC, cited by four out of five respondents, followed by lack of flexible software, convincing cost justification, lack of critical mass, and lack of education (each cited twice). In Finland, on the other hand, the major problems are perceived differently. Inflexibility in available software and hardware and lack of education were each cited three times, and security concerns, resistance to chance, and political issues surrounding telecommunications restriction were mentioned twice each.

\subsection{Legal Issues}

"The legal issues are not that difficult; international trade has been around for a long time. Legal issues are more of a perception, as they have been and can be. If different legal systems do not inhibit paper-based business, why should it, for example, inhibit EDI-based business?" (HK Tradelink). "The government is active in helping to improve the trade process. If there is an issue arising from, say, a paper document, efforts are made to trace the process and resolve the problem. This may entail changing the laws. In the past, there were some difficulties in the legal issues surrounding electronic-based commerce activities, but they have been identified and solved. There are no major problems now" (HK ITSD). "Differing legal systems in different countries is the biggest barrier to the proliferation of electronic commerce" (Finnish ISP). The legal environment for electronic trading includes the local legal tradition and even the inherent effectiveness of the legal system generally [14]. There may be a lack of effective legal mechanisms for settling disputes in electronically mediated commerce. Foreign trade may face problematic legal reciprocity and compatibility across the host countries' differing legal systems and regulations, with the multivariate laws of different scope and detail [6, 14].

Where ITs become a necessary aspect of business, their legal protection through patent and trademark laws becomes more important. Furthermore, computer records may not be acceptable as legal evidence due to the difficulties in proving authentication of electronic transmissions. Treaties with foreign nations typically impact any trade processes and in the future may incorporate more involvement with matters concerning direct transactions in data or processed information. The transnationality of information forms the basis for conflicts of law, and no regime exists to deal with such issues [4].

Because the Internet is not constrained by political boundaries, GEC is not adequately defined by existing laws or regulated by one government entity [2]. Many businesses and consumers are still wary of conducting extensive business over the Internet because of the lack of a predictable legal environment governing transactions. This is particularly true for international commercial activity, in which concerns about enforcement of contracts, liability, intellectual property protection, privacy, security, and other matters have caused businesses and consumers to be cautious [29]. Furthermore, some governments' initial efforts to tax Internet commercial activities have resulted in numerous instances in which even the basic definitions of sale and use tax regulations have been found inadequate [2]. 
The biggest vacuum in the legal framework for electronic commerce is the lack of verifiable means for identities and transactions - aptly identified by U.S. Department of Treasury officials as the "weak correspondence between computer domain name and reality" ([2], pp. 497-498). Guaranteeing the user's privacy is of prime importance in building trust in electronic commerce, but privacy rules differ from country to country and from region to region $[8,23]$.

Advertising and copyright laws also differ significantly by country [30]. The treaties concluded at the World Intellectual Property Organization in December 1996 are a step toward protecting copyright on products that are delivered electronically [23].

In this study, we found that there are some concerns regarding the legitimacy of electronic signatures in some countries. This is of particular concern to trade organizations such as HK Tradelink, where source documents originate from different countries. Because this is a critical point, both Finland and Hong Kong have taken the stance of many other countries (e.g., the United States) on this issue in declaring electronic signatures legally binding.

In the USA ISPs are treated as common carriers, and the basic attitude is that one cannot be responsible for what one cannot control. In Europe this is not always the case, and in the extreme an ISP might be responsible for something it is not allowed to control. Finnish ISP

Numerous (legal) problems exist, but none are big-each country has its own rules. Thus we have to define rules within our system appropriate to different countries we serve. HK ISP

The biggest legal problem from ISPs' point of view relates to the question of responsibilities on the Internet. Legal issues surrounding regulations concerning electronic contracts and resolution mechanisms for settling disputes in electronically mediated commerce are yet to be solved. Conceivably there may be issues related to patent and trademark laws that could not be resolved by traditional conflict resolution means.

In addition, questions related to cryptography are problematic. In many countries there are still confusions about legislation concerning public key encryption and enforcement at an international level. The stance on encryption adopted by different countries varies widely; for example, in the United States, authorities want to reserve the right to identify all the parties trading electronically, whereas in Finland it is felt that encryption in this regard should be permissible. Stated succinctly, because the nature of the world is such that each country sets its own trade and commerce rules, the internationally active organizations dealing in GEC need to grapple with intercountry legal issues. For example, HK ISP has taken pains to embed legalistic rules in programs to accommodate requirements of different countries. Similarly, HK Bank has recognized the difficulties related to intercountry legal issues, and as such, has left the resolution of the specifics and details of such issues up to their geographically dispersed offices in more than 70 countries across the world. 


\section{CONCLUSIONS}

This is a first attempt to compile the fragmented knowledge on the barriers to GEC and to empirically assess these barriers from the key players' points of view. Current electronic commerce literature is largely concentrated on possible benefits and gains of electronically mediated trade, and earlier discussion on barriers or inhibitors to GEC has been concentrated around the technical and legal issues. These issues are, as shown in this study, of high importance but not the only ones.

The results of this study show that there are some universal barriers faced by most of the respondents in both countries. In addition, there are several barriers that are specific to each country. On the surface, this seems to be natural given that different countries are at different stages of development vis-à-vis GEC. However, a closer examination of the results of this study points to certain discernible cultural factors that may have an important bearing on the diffusion of GEC. These factors encompass almost the whole spectrum of the issues presented in Figure 1 and discussed throughout the article. Because true GEC requires unrestricted access by all possible nodes in a virtual world of commerce, the presence of certain barriers even only in a few participating nodes would adversely affect the proliferation of GEC worldwide. These impediments consist of the following:

- Technical issues, such as lack of adequate infrastructure in some of the countries.

- Organizational issues, such as resistance to change.

- Economic issues, such as cost justification of GEC.

- Political issues, such as limited control or limited access to the Internet in certain countries.

- Cultural issues, such as resistance to online shopping in some parts of the world.

- Legal issues, such as the acceptance of electronic signatures in some countries.

As more and more organizations adopt GEC into their global value chain, and as more countries learn about the potentials of GEC as a facilitator for boosting international trade, one should expect to see the gradual removal of the barriers identified in this study. It is worth mentioning that many less prominent issues were cited during the course of the interviews but were not identified as key issues. It is possible that certain widely held beliefs about barriers to GEC are merely perceptions created by populism associated with major paradigmatic technological shifts.

The results of this study provide insight into the order of importance of some of the GEC issues discussed in the literature. In addition, the study sheds light on some new issues that have not received due attention in the literature.

Technical issues still dominate the hierarchy of barriers to GEC. In accord with the general thinking in the literature (e.g., [5]) we found that in both Hong Kong and Finland, infrastructural issues, as well as standards and security issues, are still key barriers to widespread adoption of GEC. In addition, we found that some companies are still faced with the problems related to integration of electronic commerce applications into the existing legacy systems. In light of the rapid 
technological developments in Internet technology, these technical obstacles should be expected to be removed gradually.

Our results highlighted the importance of two important organizational issues: resistance to change and lack of management commitment. Even though these issues have not specifically been discussed in the electronic commerce literature, they have long been acknowledged in the information systems literature.

Economic, political, and legal issues surrounding electronic commerce have been covered by other studies. For example, Applegate et al. [5] highlighted the importance of public policy, legal, and privacy issues as well as the infrastructural issues. This study not only confirms the significance of these issues, but it also stresses the influential role of government and industry championship in the GEC adoption process. Furthermore, the ever increasing importance of interagency and intercountry coordination in resolving the outstanding legal, political, and technological issues related to GEC are underscored in this study.

Finally, specific cultural issues such as language and shopping habits will affect global acceptance and diffusion of electronic commerce. Recent literature has provided tentative evidence that cultural mismatches between a country within which a system is designed and a country in which the system is used may lead to the failure of the system [31]. The result of this study also leads to the conclusion that cultural nuances are critical in understanding the complex process of GEC adoption and proliferation.

Apart from practical implications for organizations using or planning to use GEC, this study highlights many questions that await academic scrutiny including the following:

- What technical building blocks are missing from a truly global electronic trade infrastructure?

- What cultural or psychological factors cause resistance to change effected by GEC?

- What are the best means of educating and heightening awareness about the business potentials of GEC?

- What specific organizational issues need to be considered in the adoption and implementation process of GEC?

- What cultural specificities need to be studied to simplify computer-mediated trade between nations?

\section{REFERENCES}

[1] R. T. Wigand, "Electronic commerce: Definition, theory, and context," The Information Society, vol. 13, no. 1, pp. 1-16, 1997.

[2] S.-Y. Choi, D. O. Stahl, and A. B. Whinston, The Economics of Electronic Commerce: The Essential Economics of Doing Business in the Electronic Marketplace. Indianapolis, IN: Macmillan Technical, 1997.

[3] B. Ives and S. L. Jarvenpaa, "Global information technology-Some lessons from practice," International Information Systems, vol. 1, no. 3, pp. 1-15, Jul. 1992.

[4] W. R. King and V. Sethi, "An analysis of international information regimes," International Information Systems, vol. 1, no. 3, pp. 1-37, Jan. 1992.

[5] L. Applegate, C. Holsapple, R. Kalakota, F. Radermacher, and A. B. Whinston, "Electronic commerce: Building blocks of new business opportunities," Journal of Organizational Computing and Electronic Commerce, vol. 6, no. 1, pp. 1-11, 1996. 
[6] D. L. Garcia, "Networked commerce: Public policy issues in a deregulated communication environment," The Information Society, vol. 13, no. 1, pp. 17-32, 1997.

[7] R. Kalakota and A. B. Whinston, Electronic Commerce: A Manager's Guide. Reading, MA: Addison-Wesley, 1996.

[8] R. Kalakota and A. B. Whinston, Frontiers of Electronic Commerce. Reading, MA: Addison-Wesley, 1996.

[9] R. Kalakota and A. B. Whinston, Eds., Readings in Electronic Commerce. Reading, MA: Addison-Wesley, 1996.

[10] V. Zwass, "Electronic commerce: Structures and issues," International Journal of Electronic Commerce, vol. 1, no. 1, pp. 3-23, 1996.

[11] J. F. Rayport and J. J. Sviokla, "Exploiting the virtual value chain," Harvard Business Review, pp. 75-84, Nov.-Dec. 1995.

[12] A. F. Farhoomand and P. Boyer, "Barriers to electronic trading in Asia Pacific," EDI Forum, vol. 7, no. 1, pp. 68-73, 1994.

[13] P. Rietveld and J. Janssen, "Telephone calls and communication barriers: The case of the Netherlands," Anuals of Regional Science, vol. 24, pp. 307-318, Apr. 1990.

[14] P. C. Deans and M. J. Kane, International Dimensions of Information Systems and Technology. Boston: PWS-Kent, 1992.

[15] G. Barnett and Y. Choi, "Physical distance and language as determinants of international telecommunications network," International Political Science Review, vol. 16, no. 3, pp. 249-265, 1995.

[16] R. K. Yin, Case Study Research: Designs and Methods. Newbury Park, CA: Sage, 1994.

[17] G. Garaway, "The case-study model: An organizational strategy for cross-cultural evaluation," Evaluation, vol. 2, no. 2, pp. 201-211, 1996.

[18] United Nations Conference on Trade and Development (UNCTD), Trade Efficiency 2000. New York: Author, 1992, p. 1.

[19] C. W. Cheung, "Strategic implications of EDI for Hong Kong," University of Hong Kong, unpublished master's dissertation, Jul. 1991.

[20] P. Auger and J. M. Callaugher, "Factors affecting the adoption of an Internet-based sales presence for small businesses," The Information Society, vol. 13, no. 1, pp. 55-74, 1997.

[21] R. I. Benjamin, D. W. de Long, and M. S. Scott Morton, "Electronic data interchange: How much competitive advantage?" Long Range Planning, vol. 23, no. 1, pp. 29-40, 1990.

[22] M. C. Swatman and P. A. Swatman, "Integrating EDI into the organization's systems: A model of the stages of integration," in Proc. of the 12th Int. Conf. on Information Systems, 1991, pp. 141-152.

[23] M. Ahtisaari, A Borderless World: Realizing the Potential of Global Electronic Commerce, speech presented at Conf. on Dismantling the Barriers to Global Electronic Commerce, Turku, Finland, Nov. 1997. Available: http:/ /www.turku.eu.net/ahtisaari.html

[24] J. McBeth, "Nuts and bolts APEC aims to attack red tape hobbling trade," Far Eastern Economic Review, vol. 157, no. 45, pp. 32-36, 1994.

[25] E. K. Clemons, S. P. Reddi, and M. C. Row, "The impact of information technology on the organization of economic activity: The 'move to the middle' hypothesis," Journal of Management Information Systems, vol. 10, no. 2, pp. 9-35, 1993.

[26] M. Nelson, "Global EDI: Details make the difference," EDI Forum, vol. 7, no. 1, pp. 78-80, 1994.

[27] S. Talmor, "Trade barriers get hooked up," Banker, vol. 144, pp. 65-67, Feb. 6, 1994.

[28] R. M. Lee and S. D. Dewitz, "Facilitation of international contracting-AI extensions to EDI," International Information Systems, vol. 1, no. 1, pp. 94-123, Jan. 1992.

[29] W. J. Clinton and A. Gore, Jr., A Framework for Global Electronic Commerce. Available http://www.whitehouse.gov/WH/New/Commerce/read.html

[30] R. Hill, "Electronic commerce, the World Wide Web, Minitel, and EDI," The Information Society, vol. 13, no. 1, pp. 33-42, 1997.

[31] E. Jordan and J. Burn, "Information systems acceptance: A consequence of culture," presented at 3rd Pacific Asia Conf. on Information Systems, Brisbane, Australia, 1997. 
APPENDIX A

Summary Description of Participating Organizations

\begin{tabular}{|c|c|c|c|c|c|c|}
\hline Organization & Code Name & Country & Sector & Summary Description of the Organization & $E D I$ & Internet \\
\hline $\begin{array}{l}\text { Governmental IT } \\
\text { service department }\end{array}$ & HK ITSD & HK & Government & $\begin{array}{l}\text { Responsible for the development and deployment of IT services with } \\
\text { the HK government; very involved in trade-related activities, } \\
\text { including their own EDI-related initiatives }\end{array}$ & Yes & No \\
\hline Commercial bank & HK Bank & $\mathrm{HK}$ & Finance & $\begin{array}{l}\text { The largest banking organization in HK with its primary business } \\
\text { devoted to trade-related finance activities }\end{array}$ & Yes & Yes \\
\hline $\begin{array}{l}\text { Developer of EDI } \\
\text { documents }\end{array}$ & HK Tradelink & HK & Trade & $\begin{array}{l}\text { A private organization concerned with the promotion of EDI and } \\
\text { IT-supported trade activity in HK and a service provide for } \\
\text { HK-based EDI activities }\end{array}$ & Yes & No \\
\hline $\begin{array}{l}\text { Internet service } \\
\text { provider }\end{array}$ & HK ISP & HK & Trade & One of the largest and most successful provider in Asia & No & Yes \\
\hline Air cargo handler & HK AirCargo & $\mathrm{HK}$ & Transport & $\begin{array}{l}\text { Responsible for nearly all air cargo activities going through HK's Kai } \\
\text { Tak Airport }\end{array}$ & Yes & No \\
\hline $\begin{array}{l}\text { Customs clearance } \\
\text { procedures and IT }\end{array}$ & Finnish Customs & FI & Government & $\begin{array}{l}\text { Government department responsible for education concerning the } \\
\text { new European Union customs regulations and directions in } \\
\text { relation to IT }\end{array}$ & Yes & Yes \\
\hline Commercial bank & Finnish Bank & FI & Finance & $\begin{array}{l}\text { Largest commercial bank in FI; also actively involved in the } \\
\text { development of Internet payment methods }\end{array}$ & Yes & Yes \\
\hline $\begin{array}{l}\text { Network services and } \\
\text { data communication } \\
\text { associations }\end{array}$ & $\begin{array}{c}\text { Finnish Network } \\
\text { Association }\end{array}$ & FI & Trade & $\begin{array}{l}\text { Operates as a cooperative forum and working forum for promoting } \\
\text { the development of telematic services in FI; also responsible for the } \\
\text { development in the field of international and national trade } \\
\text { procedures, EDI and the United Nations EDIFACT }\end{array}$ & Yes & Yes \\
\hline $\begin{array}{l}\text { Internet service } \\
\text { provider }\end{array}$ & Finnish ISP & FI & Trade & FI subsidiary of the largest European provider & No & Yes \\
\hline Wholesaler & $\begin{array}{l}\text { Finnish } \\
\text { Wholesaler }\end{array}$ & FI & Trade & $\begin{array}{l}\text { FI's largest central distributor of products (e.g., foodstuffs, consumer } \\
\text { goods, construction material, agricultural products, and vehicles) }\end{array}$ & Yes & No \\
\hline
\end{tabular}

Note. EDI = electronic data interchange; IT = information technology; HK = Hong Kong; FI = Finland; EDIFACT = Electronic Data Interchange for Administration, Commerce, and Transportation. 


\section{APPENDIX B \\ Detailed Description of Participanting Organizations}

\section{HK ITSD}

Hong Kong, with a land area of a mere 1,000 square $\mathrm{km}$ and a population of $6.2 \mathrm{mil}-$ lion people, is the world's eighth largest economy. With its role as a major financial area and shipping port, trade activity represented US \$366 billion in import, export, and reexport activities in 1996.

The Hong Kong government is the largest employer in Hong Kong with just over 180,000 employees or $6 \%$ of the labor force. HK ITSD is mandated to support the government IT infrastructure and its trade-related activities. The role of HK ITSD department is multifold. It covers a wide range of activities, including (a) development of policies on governmental use of IT, (b) establishment and support of the IT infrastructure within the government as a whole, (c) provision of general IT services for individual departments within the government, and (d) the development and life-cycle support of specialized IT projects for individual government departments. HK ITSD supports the more than 70 government bodies (branches and departments) within the Hong Kong government.

To provide a perspective and scale of ITSD, its operations involve about 700 programmers, systems analysts, computer operators, and data entry clerks. The operating budget of HK ITSD for fiscal year 1995-1996 was US \$173 million. The valuation of the computer equipment within the government was US \$386 million at the end of 1996.

HK ITSD is involved in the computerization of trade activities within the Hong Kong government. As trade activity grows with the existing high volume of trade transactions in Hong Kong, HK ITSD's role is expected to increase as well. Additionally, they will be involved in the regulatory mechanisms in Hong Kong that will promote GEC.

\section{HK Bank}

Hong Kong is globally recognized as a major financial establishment in Asia and around the world. A valuation of its total external banking assets exceeding US \$700 billion makes Hong Kong one of the largest banking centers in the world, with HK Bank as one of the largest and most profitable banking conglomerates in the world. Ranked third in the world in terms of assets (more than US $\$ 370$ billion), it boasts more than 3,400 offices in 77 countries.

HK Bank is heavily involved in international trade activities and has invested in the operations of HK Tradelink. With respect to consumer-level activities, they are involved in e-cash suitable for electronic commerce, establishing the Mondex e-cash system in selected shopping malls in Hong Kong.

The chief executive officer leading HK Bank is an IT visionary whose background included installing HK Bank's first computer in 1966. He has helped to make HK Bank one of the most advanced in terms of electronic services to customers. They are recognized for their highly sophisticated electronic banking system including their highly regarded phone banking system. Their proprietary banking 
information system, Hexagon, among other things, is capable of interfacing with the Microsoft personal finance package MS Money, allowing integrative online banking services and personal financial management.

\section{HK Tradelink}

HK Tradelink is a private company concerned with providing EDI service for international trade in Hong Kong. The EDI systems have begun to go online. It is sponsored by large local and international conglomerates such as HK Bank and HK AirCargo to name two. The Hong Kong government has provided for $48 \%$ of HK Tradelink's funding.

HK Tradelink was established in the late 1980s, and it has recently become operational. Historically embattled with a bureaucratic tug-of-war with some of the nine involved Hong Kong government agencies, it has started to handle some of the 14 million trade declarations a year processed in Hong Kong. The annual overhead cost of paperwork alone is estimated to be US $\$ 10$ billion, which represents about $5 \%$ of the cost of trade in Hong Kong.

HK Tradelink has garnered some publicity in news articles and even as a business case. The Hong Kong government has determined that the need for EDI is real and has injected US \$55 million into HK Tradelink. It is envisioned that a significant amount of trade and eventually GEC activity in Hong Kong will pass through HK Tradelink operations.

\section{HK ISP}

Trends indicate that the numbers of Internet users in Hong Kong are growing quite rapidly, from 35,000 users in 1995 to an estimated 450,000 users in 1997, one of the fastest growing rates in Asia. One of the leading ISPs promoting the Internet has been HK ISP in Hong Kong. HK ISP is a subsidiary of a much larger business group that is devoted to information and communication services.

Starting the company with only four employees, HK ISP has grown to over 60 people in the course of a few months. To distinguish itself from the many ISPs popping up all over Hong Kong and Asia, HK ISP has developed its own proprietary member services and content. These proprietary services mimic to some degree the value-added services found in the U.S.-based America Online, which also operates through proprietary access software. To register as a member of HK ISP, a credit card is required to allow online shopping through electronic catalogs. HK ISP claims that their in-house-developed access software can handle electronic transactions more securely than the open Internet.

Identifying a gap in the fast-growing content market, HK ISP noted that most of the world's largest Internet services (America Online, Compuserve, Prodigy, Microsoft Network, etc.) are largely ignoring Asian-language content. To quickly capitalize on this, HK ISP set its sights on becoming the central clearinghouse for Asian Internet publishing and home shopping. Taking this initiative, it has expanded quickly through acquisitions and establishment of new ISPs in other Asian countries. Currently, HK ISP has expanded into markets in the Philippines, Taiwan, Malaysia, and Singapore, supporting different languages. 
HK ISP has a strong vested interest in GEC, viewing its customer base to be all of Asia plus the Asian populations in other parts of the world (e.g., the United States, Canada, and Europe). Although a bulk of the company's income is from subscribers and marketers, it foresees a revenue base from electronic commerce activities, deemed both a growth base and a source of market differentiation.

\section{HK AirCargo}

Acknowledged worldwide as the second busiest international cargo airport, Hong Kong's Kai Tak Airport boasts a fast and efficient operation. At the forefront of this operation is HK AirCargo. HK AirCargo has become the primary provider of cargo handling services to all the airlines that come through Hong Kong. Its services include the basic loading and offloading of goods, storage, distribution, and information processing. Operating $24 \mathrm{hr}$ at Kai Tak, HK AirCargo supports more than 60 airlines that pass through Hong Kong.

HK AirCargo presently operates two terminals at Kai Tak, processing 1.5 million tons of cargo per year. To better appreciate the scale of its operations, HK AirCargo has invested on the order of US \$256 million in its two-terminal operations (not including the cost of the land), one of the largest investments in air cargo facilities in the world. The nature of the goods being shipped by air cargo represents approximately $20 \%$ of the value of all cargo that passes through Hong Kong, yet only about $1 \%$ in terms of tonnage.

Started in 1976, HK AirCargo has been growing steadily at about $10 \%$ annual growth. The company's investment in information technology has helped it to achieve a measured mishandling rate of 1 in 26,000, which is considered exceptional when compared with mishandling rates of 1 in 23 found at many other international airports. Furthermore, as an early adopter of EDI technology, the company has built up its own proprietary system called the AirCargo Network. This network is linked and shared with various air-shipping-related organizations.

Hong Kong is currently building the world's most expensive airport, Chek Lap Kok, which will replace Kai Tak. HK AirCargo is investing US \$1 billion in a "superterminal" at Chek Lap Kok, which will provide it with the ability to handle 2.6 million tons of air cargo annually. This level of investment is an indication of the commitment of the company to the future, and represents a vote of confidence for Hong Kong as it changed sovereignty to mainland China in 1997.

An example of IT initiatives in HK AirCargo is their cargo tracking function called COSAC, which, like other carriers, provides customers the ability to track their cargo in transit. Using EDI, proprietary value-added networks, and facilities on the Internet, HK AirCargo also provides GEC-related services to its major customers and strategic partners in other nations.

\section{Finnish Customs}

The Customs Clearance Procedures and Information Technology Department is a unit of the Finnish National Board of Customs. It is responsible for communicating 
and educating Finnish international trade firms and organizations on customs regulations and standards adopted by the European Union (EU). Information on the Finnish National Board of Customs is also available on the World Wide Web, where they publish a variety of official notices and bulletins.

Customs deals with both import and export activities, but so far only the import clearances are computerized at a level of about $50 \%$. The export clearance procedures are also planned to be automated to EDI in the near future. In addition to import and export activities, connection to the centralized EU customs tariff quota database (TARIC) in Brussels has been established. This allows statistical information on EU members' trade activities and regulations pertaining to import of products into the EU and some exports to be communicated to them automatically. Such electronic-based activities serve to establish fair trade practices among the 15 members of the EU.

Besides the traffic and trade across the external borders of the EU, imports and transit movements are also monitored by Customs. This allows the Finnish government to ensure excise taxation in the internal market.

\section{Finnish Bank}

The Finnish Bank was formed in June 1995 from the merger of the largest commercial banks in Finland. Being part of a publicly listed company on the Helsinki Stock Exchange, the bank represents the group's largest subsidiary. The balance of the group's business involves commercial real estate, brokerage services, and insurance. The Finnish Bank is a full-service operation, providing a wide range of financing, payment, and asset management services for individuals, companies, and institutions. On a global scale, its services are primarily oriented to Finnish and Scandinavian firms.

The Finnish Bank is heavily vested in providing electronic (telematic) banking services for both individuals and businesses. Their well-received and highly touted electronic payment facility is now operational on the World Wide Web. It enables its customers to shop and pay for purchases through the Internet. Presently the company is signing on many online businesses to offer its payment services. The bank is expected to also have a strong presence in e-cash services.

\section{Finnish Network Association}

There are a number of network and telecommunications associations in Finland. Although independent, these firms work cooperatively. Two such organizations that share common office areas are the Finnish Association for Interactive Network Services (Telmo) and the Finnish Data Communication Association (FDCA).

Telmo was established in 1992 to promote the development of telematic (online and telecommunications) services throughout Finland. Telmo operates as a cooperative forum and as a working group for its members. Members include telecommunications service providers, network operators, system vendors, government ministries, and end-user customers. 
Telmo serves to maintain and communicate a set of guidelines, standards, and codes of practice in the area of information networks and network services. Its roles in the promotion of telecommunications include conducting marketing studies, collecting of statistics, and offering seminars for its members. Close cooperation with the member companies, including the FDCA, and its ability through membership to influence the work have proven to be a successful path for the promotion and implementation of EDI.

The FDCA, in accordance with the statutes of the organization, has the responsibility for the development of international and national trade procedures for Finland, including support for standards such as United Nations EDIFACT. Its organizational standing is recognized by the Ministry for Trade and Industry, the Ministry for Communications, and the Ministry for Foreign Affairs as the national expert organization in trade facilitation and EDI. The FDCA has 98 supporting members, the majority of which are firms using EDI. Besides standards work, promotion of EDI stems from its support and operation of the EDI Users Club, representing the largest organized group of EDI users in Finland with a membership of approximately 900 .

\section{Finnish ISP}

The Finnish ISP is a wholly owned subsidiary of the largest ISP in Europe. The parent company currently operates in 41 countries in Europe as well as the former Soviet Union and Northern Africa. The Finnish ISP itself is a relatively small operation, with 15 or so employees. Nonetheless it has experienced a 300\% to $400 \%$ growth during its past few years of operation.

The main business focus of Finnish ISP is the provision of high-quality Internet services primarily targeted to the business user. Progressive to its strategy, it has sought to offer

value-added services to its customers and as a means to be more competitive. Thus in March 1996, the Finnish ISP and DigiCash, the leading innovator in electronic payment technology, launched a system that lets consumers make and receive payments over the Internet using an electronic form of cash. This e-cash technology gives even very small payments of a few cents the level of security once reserved exclusively for large-denomination wire transfers. The e-cash service has all the flexibility and familiarity of irrefutable, private, and person-to-person payment capability of paper money.

The DigiCash system is first being launched in Finland, a logical decision by the company because Finland has one of the highest numbers of Internet connections per capita in the world. Finland's largest bank is also a partner in the DigiCash system. Their electronic payment service for account holders provides each customer with the ability to withdraw money directly from his or her bank account into an e-cash electronic "purse." This allows the 3,000,000 potential account holders the ability to visit a "virtual ATM" on the World Wide Web and to make electronic payments online to a wide variety of merchants ranging from major magazines, news companies, and stock quote servers to e-mail-based global system for mobile communications (GSM) paging. The Finnish ISP, being part of a 41-country international business, is continuing its success in this global commerce initiative in 
working with other major banks to provide international transactions with currency exchange capability.

\section{Finnish Wholesaler}

Finnish Wholesaler is Finland's largest central distributor of foodstuffs and consumer goods as well as construction material, agricultural products, and vehicles. Its customers are 2,800 independent retail stores through Finland as well as industry, government institutions, and large food service operators. As a central distributor, the Finnish Wholesaler produces, warehouses, delivers, and invoices its products so that independent stores can gain value from the group affiliation.

The Finnish Wholesaler had an early start in electronic transactions for its customers, and by 1992 had implemented EDI services between the group and the retailers. Today the Finnish Wholesaler has about 500 EDI partners. About $90 \%$ of its turnover goes through the information networks, including all the suppliers and other partners. Indeed, about half of the EDI traffic in Finland involves the Finnish Wholesaler.

Continued investment in IT for improving its logistical operations has brought significant savings in terms of warehouse and transportation costs to the Finnish Wholesaler. The Finnish Wholesaler is currently evaluating a range of possible customer services that can be provided over the Internet. 